East African Medical Journal Vol. 83 No. 12 December 2006

SOCIO-DEMOGRAPHIC CHARACTERISTICS OF PATIENTS ADMITTED WITH GYNAECOLOGICAL EMERGENCY CONDITIONS AT THE PROVINCIAL GENERAL HOSPITAL, KAKAMEGA, KENYA

E.B. Wamwana, MD, MMed, Specialist Obstetrician and Gynaecologist, Pumwani Maternity Hospital, P.O. Box 4284900100, Nairobi, Kenya, P.M. Ndavi, MBChB, MMed, MSc. Epid, DLSHTM, FHBR, Senior Lecturer, P. B. Gichangi, BSc, (Anatomy), MMed, PhD, Senior Lecturer, Department of Human Anatomy/Obstetrics and Gynaecology, J.G. Karanja, MBChB, MMed, Associate Professor, Department of Obstetrics and Gynaecology, College of Health Sciences, University of Nairobi, P.O. Box 19676-00202, Nairobi, Kenya, E.G. Muia, MBChB, MPH, DrPH, Programme Associate, Population Council, Nairobi, Kenya and G.W. Jaldesa, MBChB, MMed, MSc, Rep. Health, Specialist Obstetrician and Gynaecologist, Kenyatta National Hospital, P.O. Box 20723-00202, Nairobi, Kenya

Request for reprints to: Dr. P.M. Ndavi, Department of Obstetrics and Gynaecology, College of Health Sciences, University of Nairobi, P.O. Box 19676-00202, Nairobi, Kenya

\title{
SOCIO-DEMOGRAPHIC CHARACTERISTICS OF PATIENTS ADMITTED WITH GYNAECOLOGICAL EMERGENCY CONDITIONS AT THE PROVINCIAL GENERAL HOSPITAL, KAKAMEGA, KENYA
}

\author{
E.B. WAMWANA, P.M. NDAVI, P.B. GICHANGI, J.G. KARANJA, E.G. MUIA and G.W. JALDESA
}

\begin{abstract}
Objective: To determine the magnitude of gynaecological emergencies and the socio demographic characteristics of patients admitted at Provincial General Hospital Kakamega (PGHK).

Design: Retrospective cross-sectional study.

Setting: Provincial General Hospital Kakamega, the referral hospital for Western Province, Kenya. Subjects: Four hundred patients admitted at the gynaecological wards during the period 1st January 2002 to 31st December 2002.

Results: In this study $80 \%$ of gynaecological patients admitted at PGH Kakamega were of an emergency nature with $45 \%$ being teenagers. The mean age was $17 \pm 3$ (mean \pm SD). The majority had primary level of education or below $(69 \%)$, unemployed $(87 \%)$ and were rural residents $(71 \%)$. Patients with abortion formed about $43 \%$ of the study group while those with inflammatory disease, pelvic abscess and ectopic pregnancy formed about $24 \%, 10 \%$ and $8 \%$ respectively.

Conclusion: Most gynaecological admissions in PGH Kakamega are of acute nature, with abortion being the most common diagnosis. Hence, trained staff, equipment, supplies and drugs for management of acute gynaecological conditions should be available in hospitals in Western Kenya.
\end{abstract}

\section{INTRODUCTION}

The Kenya Government set up the National Reproductive Health Strategy (NRHS) in 1996 (1) as a response to the Safe Motherhood International Conference held in Nairobi in 1987 followed by the 1994 Cairo Conference on Population and Development (ICPD). Among its components, are; management of STI, HIV/AIDS, promotion of adolescent and youth health, gender issues, reproductive rights and Safe Motherhood which includes abortion (2).
Abortions significantly contribute to $50-60 \%$ of acute gynaecological conditions $(3,4)$, as shown in studies in Nairobi and Lesotho. In the Lesotho study, about $25 \%$ of maternal deaths were secondary to complications of abortions. Contributing factors to unsafe abortion included, educational needs, failed contraception, stigma attached to child bearing out of wedlock, lack of support from spouse/family, religion and lack of family planning services for adolescents (4).

Different gynaecological conditions present as acute conditions (3-6). Uterine prolapse and pelvic 
inflammatory disease (PID) accounted for $19 \%$ and $13 \%$ respectively in a study of 717 women with gynaecological conditions at the Aga Khan University, Karachi, Pakistan in 1992 (5). The prevalence of uterine prolapse (adjusted odds ratio 1.8; 95\% confidence interval 1.0-3.0) was significantly higher among women who married at younger age i.e. 16 years and below independent of education, socioeconomic status and parity. PID was significantly higher among those under 21 years of age (adjusted O.R 2.3;95\% C.I 1.1-4.8). Pelvic inflammatory disease with its immediate complications of pelvic abscess, peritonitis, endotoxic shock and long term complications of ectopic pregnancy alongside induced abortion with post abortal haemorrhage, sepsis and bleeding due to gynaecological tumours were the acute gynaecological conditions that women presented with in a study in rural Gambia tertiary medical institution (6).

A strong relationship between pelvic inflammatory disease (PID) and STD/HIV / AIDS was demonstrated in a study of 133 women in KNH in 1997 (7). Close to $38 \%$ of the women were HIV positive, $31 \%$ were positive for gonorrhoea, $16 \%$ had trichomonas infections and $7 \%$ had syphilis. In this study $50 \%$ of contact partners, had an STD of whom $42 \%$ had concurrent infections with their female partners. In comparison with the control group, they were younger, less educated and had more sexual partners. The study concluded that tracing contact partners of PID patients, empirical treatment and counseling should be an integral part of PID management.

In the epidemiology of induced abortions in Nairobi, $60 \%$ of gynaecological emergency cases at Kenyatta National Hospital were abortions out of which $53 \%$ were under 14 years of age (8). Studies show that a large percentage of the high maternal mortality are due to complications of abortion (8-10). While the quality of care for patients with acute gynaecological conditions remains a major concern in most rural hospitals with few having required investigations undertaken and or receiving the necessary timely surgical interventions (11), bed occupancy in a health delivery system is a major concern. An average of 91 hours bed occupancy for septic abortions as compared to 39 hours for nonseptic conditions was demonstrated in a review of abortions in KNH in 1980 (12). The use of Manual Vacuum Aspiration (MVA) (13), even in primary health care facilities, to minimise the risk of abortion turning septic can drastically reduce bed occupancy since in most cases this can be an outpatient procedure.

However the contribution of acute gynaecological conditions to female morbidity/ mortality in Provincial General Hospital, Kakamega is unknown, thus the need to study the magnitude of gynaecological emergencies and the sociodemographic characteristics of patients admitted at this hospital. The centre is an ideal place since it is the referral hospital for eight districts of Western Province among which is Vihiga with one of the highest fertility rates in Kenya.

\section{MATERIALS AND METHODS}

Study design: A retrospective review of the records of patients seen in the gynaecology ward during a period of one year between 1st January 2002 and 31st December 2002 was undertaken.

Study area: The study was carried out at the Provincial General Hospital, Kakamega where the principle investigator represented the University of Nairobi in the Safe Motherhood Demonstration Project in the capacity of a registrar in obstetrics and gynaecology between March and November 2001.

Study population: All patients admitted to the hospital with a diagnosis of acute gynaecological ailment. These included cases of abortion, genital tract infections, rape, imperforate hymen with haematocolpos, ectopic pregnancy, abnormal uterine bleeding, and torsion of ovarian cyst admitted between 1st January 2002 and 31st December 2002.

Sample size: The following formula was used to calculate sample size.

$$
\begin{aligned}
\mathrm{N}= & \frac{\mathrm{Z}^{2} \mathrm{P}}{\mathrm{C}} \\
\mathrm{N}= & \text { desired sample size } \\
\mathrm{Z}= & 1.96 \text { at } 95 \% \text { confidence level } \\
\mathrm{P}= & \text { prevalence rate (here taken as } 50 \% \text { of all } \\
& \text { gynaecological admissions being of acute } \\
& \text { nature as shown in studies in } \mathrm{KNH} \text { and } \\
& \text { Lesotho) } \\
\mathrm{C}= & \text { Precision with which to estimate } \mathrm{P}=5 \%, \\
\mathrm{~N}= & 384 \text { rounded to } 400 .
\end{aligned}
$$


Study instruments: A structured questionnaire comprising of close-ended questions and precoded responses was used. A number, omitting the name for ethical reasons, identified each questionnaire (to avoid breach of confidentiality). Sources of information were from admission and discharge/ death registers, theatre notes and patient's files retrieved from the records department.

Data collection: All the files of eligible cases were retrieved tracing them from the admission book of the gynaecology ward. Four hundred cases were sampled randomly and information entered in the questionnaire by the study nurse. The total number of admissions in the gynaecology unit was recorded. Data collected included socio-demographic status, diagnosis, treatment options and outcome of treatment.

Data analysis: Data were counter checked and proofread before being entered in the computer. Analysis was undertaken using computer statistical package i.e. SPSS-PC package.

Eligibility criteria: All patients admitted with a diagnosis of acute gynaecological ailment.

Exciusion: Cases with inadequate information.

Ethical consideration: Permission to carry out research was sought from the ethical and research committee, Ministry of Education, Science and Technology and PMO Western Province. The case files were precoded and no names were used. All information obtained from the study was treated in confidentiality and used only for the intended purposes. All questionnaires were identified by serial numbers not patienit name.

\section{RESULTS}

A total of 537 patients with gynaecological conditions admitted at the Provincial General Hospital Kakamega between 1st January and 31st December 2002 were recorded in the admission book. Five hundred corresponding files were retrieved from the registry, giving a retrieval rate of $93 \%$. Out of these 400 were of acute nature i.e. $80 \%$.
Table 1 shows that about half of the cases admitted with acute gynaecological conditions were teenagers ( $45 \%$ ). Those aged between $20-24$ years constituted $9.5 \%, 40 \%$ were aged between $25-40$ years and $5.5 \%$ were above 40 years of age. The mean age was $17 \pm 3$ years (Mean $\pm \mathrm{SD}$ ). The majority of patients had between zero to two previous deliveries $(66.8 \%)$ with a mean of one previous delivery. Majority of the cases $(60 \%)$ were either unemployed or housewives, while students formed $17.5 \%$. The self-employed group formed $9.0 \%$, while public servants; private firm employees and house helps formed $13.5 \%$. About $50 \%$ of the cases were educated up to primary school level. Those with secondary school education and above were $28 \%$ while woman with no formal education were $22 \%$. Close to $71 \%$ of the cases resided in rural areas and $29 \%$ in urban region.

Abortion comprised of about $43 \%$ of all cases admitted with acute gynaecological conditions while pelvic inflammatory disease and pelvic abscess accounted for close to $34 \%$ of the cases. Cases with puerperal sepsis accounted for $10 \%$ while ectopic pregnancies formed $7.5 \%$ of the cases while abnormal uterine bleeding contributed $5 \%$, Bartholins abscess, imperforate hymen with haematocolpos and dysfunctional uterine bleeding accounted for $1.5 \%$ (Table 2).

As shown in Tables 3 and 4, majority of patients with abortion (51\%) and pelvic inflammatory disease and abscess (59\%) were under 20 years of age. Almost two out five patients and three out five patients with abortion and PID/abscess, respectively were single and $69 \%$ and $83 \%$ of patients with abortion and PID/abscess respectively had either no formal education or were primary school leavers. Unemployed women and housewives constituted a big majority of the patients with abortion $(71 \%)$ while these accounted for $52 \%$ of the women admitted with PID/pelvic abscess. Rural residents formed about $65 \%$ and $79 \%$ of the patients respectively with abortion and PID/ abscess. Housewives and unemployed women account for. Students accounted for $26 \%$ while house helps constituted $10 \%$. Rural residence constituted $79 \%$ of women with PID/pelvic abscess. 
Table 1

Socio-demographic characteristics of women admitted in acute gynaecology ward

\begin{tabular}{lrr}
\hline Variable & No. $(\mathrm{n}=400)$ & $(\%)$ \\
\hline Age (years) & 166 & 45 \\
$<20$ & 42 & 9.5 \\
$20-24$ & 160 & 40 \\
$25-40$ & 23 & 5.5 \\
$>40$ & & \\
Previous deliveries & 130 & 32.5 \\
0 & 201 & 50.4 \\
$1-4$ & 69 & 17.2 \\
25 & & \\
Occupation & 239 & 60.0 \\
House wife/unemployed & 70 & 17.5 \\
Student & 36 & 9.0 \\
Self-employed & 20 & 5.0 \\
Public/civil servant & 14 & 3.5 \\
Private firm employee & 20 & 5.0 \\
House help & & \\
Education & 89 & 22.0 \\
None & 209 & 50.0 \\
Primary & 112 & 28.0 \\
Secondary and above & & \\
Place of residence & 285 & 71.0 \\
Rural & 115 & 29.0 \\
Urban & & \\
\hline & & \\
\hline
\end{tabular}

Table 2

Morbidity pattern in acute gynaecology ward

\begin{tabular}{lcr}
\hline Category of clinical conditions & No. $(\mathrm{n}=400)$ & $(\%)$ \\
\hline Abortion & 170 & 42.5 \\
Ectopic & 30 & 7.5 \\
Pelvic inflammatory disease & 94 & 23.5 \\
Abnormal uterine bleeding & 20 & 5.0 \\
Bartholins abscess & 4 & 1.0 \\
Puerperal sepsis & 40 & 10.0 \\
Pelvic abscess & 40 & 10.0 \\
Imperforate hymen with haematocolpos & 1 & 0.25 \\
Dysfunctional uterine bleeding & 1 & 0.25 \\
\hline
\end{tabular}


Table 3

Distribution of characteristics of patients with abortion

\begin{tabular}{lcc}
\hline Variable & No. $(\mathrm{n}=170)$ & $(\%)$ \\
\hline Age (years) & 87 & 51.0 \\
$<20$ & 66 & 39.0 \\
$20-24$ & 17 & 10.0 \\
$\geq 25$ & & \\
Marital status & 70 & 41.0 \\
$\quad$ Single & 100 & 59.0 \\
$\quad$ Ever married & & \\
Education & 34 & 20.0 \\
$\quad$ None & 84 & 49.0 \\
Primary & 62 & 31.0 \\
Secondary and above & & \\
Occupation & 120 & 70.6 \\
$\quad$ Housewife/unemployed & 25 & 15.0 \\
Student & 13 & 7.5 \\
Self employed & 8 & 4.5 \\
Public/civil servant & 3 & 1.7 \\
$\quad$ Private firm employee & 1 & 0.7 \\
House help & & \\
Place of residence & 110 & 64.7 \\
$\quad$ Rural & 60 & 35.3 \\
$\quad$ Urban & & \\
&
\end{tabular}

Table 4

Distribution of characteristics of patients with pelvic inflammatory disease and pelvic abscess (PID/abscess)

\begin{tabular}{lcc}
\hline Variable & No. $(\mathrm{n}=134)$ & $(\%)$ \\
\hline Age (years) & 79 & 58.8 \\
$<20$ & 31 & 23.4 \\
$20-30$ & 24 & 17.6 \\
$\geq 31$ & & \\
Marital status & 78 & 58.0 \\
$\quad$ Single & 56 & 42.0 \\
Ever married & & \\
Education & 31 & 23.0 \\
None & 79 & 60.0 \\
Primary & 24 & 17.0 \\
Secondary and above & & \\
Occupation & 70 & 52.0 \\
Housewife/unemployed & 35 & 26.0 \\
Student & 8 & 6.0 \\
Self employed & 3 & 3.0 \\
Public /civil servant & 4 & 3.0 \\
Private firm employee & 13 & 10.0 \\
House help & & \\
Place of residence & 106 & 79.0 \\
Rural & 28 & 21.0 \\
Urban & & \\
\hline
\end{tabular}


Table 5

Distribution of characteristics of patients with puerperal sepsis in acute gynaecology ward

\begin{tabular}{lrr}
\hline Variable & No. $(\mathrm{n}=40)$ & $(\%)$ \\
\hline Age (years) & 4 & 10.0 \\
$<24$ & 33 & 82.5 \\
$24-40$ & 3 & 7.5 \\
$>40$ & & \\
Marital status & 10 & 25.0 \\
$\quad$ Single & 30 & 75.0 \\
Ever married & & \\
Education & 15 & 37.5 \\
None & 16 & 40.0 \\
Primary & 9 & 22.5 \\
Secondary and above & & \\
Occupation & 20 & 50.0 \\
$\quad$ Housewife/unemployed & 1 & 2.5 \\
Student & 10 & 25.0 \\
Self employed & 5 & 12.5 \\
Public /civil servant & 4 & 10.0 \\
Private firm employee & 0 & 0.0 \\
House help & & \\
Place of residence & 25 & 62.5 \\
Rural & 15 & 37.5 \\
Urban & &
\end{tabular}

Majority of patients admitted with puerperal sepsis were aged between 24 and 40 years. Adolescents constituted $10 \%$ while $75 \%$ were married. The level of education was evenly distributed between none to secondary and above education. Half of the women in this group were either housewives or unemployed and $62.5 \%$ were rural residents.

\section{DISCUSSION}

In this study, the total number of retrieved case files of gynaecological patients admitted at the Provincial General Hospital Kakamega between $1^{\text {st }}$ January 2002 and $31^{\text {st }}$ December 2002 was 500, of which 400 were of an acute nature i.e. $80 \%$. About half of these women ( $45 \%$ ) were teenagers with a mean age of $17 \pm 3$ years. This falls within the adolescent group, suggesting an early age of sexual activity, and compares with a study in Pakistan where young women were found to have immense burden of reproductive health ailments especially those who began sexual activity at an early age. The majority of women was of low socio-economic status with either primary school education or none at all, no gainful employment and resided in rural areas. In the Nyahururu study (11), set in a similar environment as in this study, respondents were more educated with $55 \%$ having attained at least secondary education. The level of unemployment was lower (69\%) in comparison with this study. This is further corroborated by data from Central Bureau of Statistics on poverty eradication where $90 \%$ of rural residents in Kakamega district live on less than one dollar per day in comparison with rural residents in Nyahururu district where $57 \%$ live on less than one dollar per day (14).

In this study, the leading acute gynaecological condition was abortion followed by PID/abscess. Elsewhere similar studies in Nyahururu showed $87.2 \%$ admitted with abortion, $\mathrm{KNH} 60 \%$, Lesotho $50 \%$, Brazil and Latin America abortion cases constituted $40 \%$ and $42 \%$ respectively $(3,4,11,15)$. This would seem to be a relatively low percentage compared to other studies until one considers the rate of attendant common abortion complications.

Poorly managed abortion can give rise to several short term and long term complications among 
which are haemorrhage, perforated uterus, post abortal sepsis, pelvic abscess, ectopic pregnancy and infertility due to tubal factor. Pelvic inflammatory disease accounted for $23.5 \%$ while pelvic abscess constituted $10 \%$ and ectopic pregnancy $7.5 \%$ of patients admitted with acute gynaecological conditions at the PGH Kakamega. In the Nyahururu study, PID accounted for $4.1 \%$, pelvic abscess $0.8 \%$ and ectopic pregnancy $3 \%(11)$.

The women admitted at the PGH Kakamega with acute gynaecological conditions came from a poorer socio-economic background than their counter parts in Nyahururu. It is interesting to note that the Kakamega group had a higher rate of PID, pelvic abscess and ectopic pregnancy than the Nyahururu one. Given that these are mostly complications of such primary conditions as abortion and lower uro-genital tract infections, the Kakamega patients reached a tertiary medical institution at a more advanced disease process, than in Nyahururu.

The demographic characteristics of women admitted at the PGH Kakamega with abortion, were similar to those with PID and pelvic abscess. The majority were young, single or in early years of marriage with inadequate formal education, not engaged in any gainful employment and residing in the rural area.

\section{CONCLUSION}

Majority of patients admitted at the PGH Kakamega in acute gynaecology unit were young, unemployed, with low parity, residing in the rural area. Abortion was the most common acute gynaecological ailment with its complications accounting for the longest hospital stay in comparison with other acute gynaecological conditions. This situation could be addressed by providing a stronger community based health care, stronger referral systems and better transport infrastructure.

\section{ACKNOWLEDGEMENTS}

To the Ministry of Health PMOs office, the staff of Provincial General Hospital, Kakamega, The Population Council, Nairobi the administrator of the SMDP and Department for International Development (DFiD) for providing the funding for the SMDP.

\section{REFERENCES}

1. Ministry of Health National Reproductive Health Strategy, 1997-2010, 1996.

2. Otsea $\mathrm{K}$. The place of abortion in safe motherhood. J. Obstet. Gynaecol. East \& Central Afr. 1993; 11: 3-7.

3. Aggarwal V.P. and Mati J.K.G. Epidemiology of induced abortions in Nairobi. J. Obstet. Gynae. East $\mathcal{E}$ Central Afr. 1992; 4: 54-57.

4. Misuse M.L. and Tlebera P. Unsafe abortion and postabortion family planning in Africa: The case of Lesotho. Afr. J. Fertil. Sexual Reprod. Hlth. 1996; 1: 26-28.

5. Sajan F. and Fikree F.F. Does early age at marriage influence gynaecological morbidities among Pakistani women? J. Bios. Sci. 2002; 34: 407-417.

6. Walraven G., Scherf C, West B., et al. The burden of reproductive disease in rural women in Gambia West Africa. Lancet. 2001; 357: 1161-1167.

7. Mugo R. The socio-demographic and bacteriologic profile of women with pelvic inflammatory disease and their sexual partners. Gynaecological long commentary. MMed Thesis, University of Nairobi, 1997.

8. Murugu N.M. A 10-year review of mortality due to abortion in KNH, 1974-1983. MMed Thesis, University of Nairobi, 1985.

9. Rogo K.O. Mortality in acute gynecology unit-clinical diagnosis. Int. J. Obstet. Gynae. 1989; 30: 343-347.

10. Ministry of Health, Population Council and University of Nairobi. Safe motherhood project: A demonstration project on approaches to providing quality maternal care in Kenya. Preliminary findings from the baseline survey of December 2000. Draft of 2001.

11. Mbugua F.K. Morbidity patterns in the acute gynaecology unit in rural District Hospital, Kenya. MMed Thesis, University of Nairobi, 1999.

12. Aggarwal V.P. and Mati J.K.G. Review of abortions in Kenyatta National Hospital. East Afr. Med. J. 1980; 57: 138-146.

13. Rogo K.O. and Kizza A.P. Assesment of MVA equipment in management of incomplete abortion. East Afr. Med. J. 1990; 67: 812-821.

14. Ministry of Planning and National Development. Poverty eradication programme. Draft Manual 1997, $1998,2000$.

15. Sweet R.L. Pelvic inflammatory disease: Aetiology, diagnosis and treatment. Sex Transm. Dis. 1981; 8: 308-315. 